\title{
Operational Challenges to Smallholder Dairy Farming: The Case of Mayfield Dairy Settlement Scheme in Chipinge District of Zimbabwe
}

\author{
Crispen D. Hahlani and Jabulani Garwi
}

\begin{abstract}
This study looked at the operational challenges to smallholder dairy farming. Focus in this study was specifically on Mayfield Small Scale Dairy Settlement Scheme in Chipinge District of Zimbabwe. The study made use of interviews, questionnaires, observations and project reports in collecting both qualitative and quantitative research data. Semi-structured questionnaires were administered to a sample of 75 farmers randomly selected from a total population of 345 family farmers on the dairy settlement scheme. In addition, 24 key informants were conveniently sampled for interviews from among the scheme's management, farmer committee leaders and extension staff. The study noted that while dairy operations at the settlement scheme managed to yield notable benefits to the farmers, there were a number of operational challenges working against full commercialization of production at the scheme. These problems bordered on lack of access to capital, poor production and marketing infrastructure, weak extension support, insecure land tenure, lack of farmer involvement in production planning and poor social relations between farmers and management on the one hand and among the farmers themselves, on the other hand. The study recommends that these problems be addressed, not only at Mayfield Dairy Settlement Scheme, but also elsewhere, if smallholder dairy operations are to serve as real tools for rural transformation in Zimbabwe and other less developed countries.
\end{abstract}

Key Words: Operational Challenges, smallholder dairy farming, Zimbabwe

\section{Introduction}

Smallholder agriculture is likely to remain one of the major sources of rural growth and livelihood improvement (World Bank, 1997). Smallholder dairy farming is an economic activity which involves keeping dairy cows with a herd of less than seven (7) milking cows on less than 1 ha of land (Henk et al., 2007). Milk production by smallholder farmers raises rural employment and incomes while at the same time helping in diversifying, intensifying and stabilizing agricultural production (Ngetha, 2000). Johnson (1996) argues that dairy development is not only important for nutrition, but can also lead to the social and economic betterment of smallholder families.

The expanding market for milk and its products in Africa has been an incentive for many farmers to engage in smallholder dairy farming. Most of the smallholder farmers are taking smallholder dairy farming as a business; they are practicing farming with the aim of maximizing profits. The Zimbabwean government has been of the view that developing smallholder dairy farming will not only improve the availability of milk and its products to the country, but will also improve the standards of living for the rural communities (Matinhira, 1988).

\section{Background to the study}

In Zimbabwe, commercial dairy production started as far back as 1912 (Matinhira, 1988: 23). However, owing to colonial policies of separate development that favoured the white farming sector, dairying was exclusively a preserve of the large scale white commercial farmers, who produced milk to satisfy the "national needs" (Gittinger, 1997). The infrastructure for dairying was also designed to supply milk and its byproducts to the urban people who accounted for only 30\% of the country's population (Slater, 1997: 17). During this period, smallholder dairying was largely for subsistence purposes (Crotty, 1999).

With the coming of independence in 1980, the Government of Zimbabwe (GOZ) expressed its commitment to the development of the smallholder dairy farming sector through increased participation of smallholder farmers in commercial milk production. This resulted in the formation of the Peasant Sector Development Programme (PSDP) ${ }^{1}$ in 1982 (Hale, 2001). The main objectives of the PSDP were: to enhance local production capacity in the smallholder dairy farm sector, to reduce the national shortfall in production for marketed milk and its products, to develop the local marketing of milk and to raise the standards of living of the

\footnotetext{
${ }^{1}$ The management of the programme was moved from the then Ministry of Agriculture to ARDA in 1989 and the programme became known as the Dairy Development Programme (DDP), (ARDA, 1989)
} 
rural farmers (Matinhira, 1988). It is against this backdrop that the Mayfield dairy scheme was established in the Eastern Highlands of Chipinge in 1985 (Mayfield Dairy Settlement Scheme, 1986: 02).

Mayfield Dairy Settlement Scheme was located in Chipinge district of Manicaland province, south east of Zimbabwe. The dairy settlement scheme, a model $\mathrm{C}^{2}$ resettlement project, covered a total land area of 6900 hectares. The Ministry of Agriculture, Mechanisation and Irrigation Development, through the Agricultural and Rural Development Agency (ARDA), a semi-governmental agency, was responsible for all administrative issues at Mayfield. Through ARDA, a scheme management team consisting of a Settlement Manager and other supporting staff was set up at the scheme to provide all the requisite administrative and technical support to the farmers. In discharging these functions, the team was expected to liaise closely with the Scheme Development Committee made up of members elected from the smallholder dairy farming community. At planning, it was envisaged that ARDA would be responsible for all aspects of scheme administration until the farmers were fully equipped to take over. The administrative functions of ARDA included the development, implementation and control of all operations at the scheme. The scheme management was also responsible for operating Milk Collection Centres and providing training and extension support to the farmers.

\section{Problem Statement}

Despite government's expressed commitment to commercialize smallholder dairy farming in Zimbabwe, the majority of dairy farmers continue to produce at a subsistence level. An average milk yield per cow per day for smallholder dairy farmers has remained low compared to what obtains in the large scale sector (Hale, 2001). Such a scenario has, no doubt, led to serious misgivings about the efficacy of smallholder dairy schemes as an instrument for rural development. Some argue that effective dairy management skills are still lacking in the smallholder dairy sector and that smallholder dairy farmers are not properly organized in the way(s) that enable them to tap into the benefits of dairy farming. Some believe that smallholder dairy farming is exploitative and virtually a tool for enslaving smallholder farmers. Others are of the view that dairy farming is only viable under large scale conditions of scale economies. It has also been widely postulated that due to their limited capacity and capabilities, smallholder dairy producers often have difficulties in exploring new market and development opportunities (Shepherd, 2007). Explanations relating to the operational challenges facing smallholder dairy farming are, thus, many and varied, with some of the explanations bordering on mere speculation.

\section{Study Purpose and Justification}

Using Mayfield Small Scale Dairy Settlement Scheme as a case study, the purpose of this study was therefore to assess the major operational challenges affecting the performance of smallholder dairy farming. In this study, a number of lessons could be drawn. Given that Mayfield Dairy Settlement Scheme was implemented as a pilot intervention in the government of Zimbabwe's quest for a 'White Revolution' through commercialization of smallholder dairy farming in the countryside, lessons drawn from this case study would help in guiding future implementation of similar schemes, not only in Zimbabwe, but also in other countries in a similar development milieu.

\section{Literature Review}

Norman and Wilson (1996) argue that the state's exploitative tendencies through surplus value extraction by market and non-market means, such as cheap milk prices, undermined smallholder farming in less developed countries. Using a specific case study of the Karega smallholder dairy farmers of Karega district in Tanzania, Cahaca (2000) criticizes the state's active role in the day to day operations of smallholder dairy farming projects. This high-handed managerial role was complemented by another sophisticated one: control of marketing. Eager to get as much as possible from the peasants and doubting the ability of smallholder dairy farmers to conduct marketing, the state, according to Cahaca (2000) casted itself as the sole purchaser of dairy produce. Similarly, Milliken (2000) noted low farmer participation as the main factor behind the poor performance of smallholder dairy farming in Bolivia as the farmers were not involved in the planning of dairy farming programmes. Using Cote d'voire as an example, Bassett (1994), concludes that the economic interests of the state are in sharp contrast with those of the smallholder farmers and that the state's extraction of wealth from the smallholder farmers is one of the reasons behind the failure of smallholder dairy farming in Africa.

\footnotetext{
${ }^{2}$ Model $\mathrm{C}$ schemes were intended to involve smallholders in intensive agricultural enterprises. In a typical Model C scheme, a core estate (government state farm) provides production and marketing services so that settlers are effectively outgrowers. All model C schemes are located in Manicaland province and by 1989 this model represented less than one percent of all resettlement areas (Roth, 1990).
} 
Extension support has also been viewed as a critical success factor in dairy farming operations. In a study of smallholder dairy farming in the rural areas of Kiambu District in Kenya, Wambugu (2007) noted a very strong relationship between contact with extension workers and the quality of the farmers' knowledge, decision making process and practice. In a related study conducted in the Kilimanjaro Highlands Mdoe and Mlay (2009) established that improved farmer access to extension services had a positive impact on the performance of dairy cattle. This was reflected in the improvement in the growth rate of young animals, better body condition of mature animals, better health status and, ultimately, increased milk production. In a study carried out in Burundi, Arusei (2012) noted that smallholder dairy farmers had varied information needs but provision of extension information was not satisfactory as most of the information needs were not met. In Mali, despite the availability of well trained and experienced extension personnel, lack of adequate transport and cumbersome bureaucratic procedures involved in accessing finances for extension work resulted in a weak link between extension staff and farmers (Mahood, 2009). Poor extension support has resulted in poor dairy management practices as noted by Mugwagwa (2001) in the case of the Marirangwe dairy scheme in Zimbabwe. Similarly, low milk production at Chikwakwa smallholder dairy scheme in the Mashonaland East province of Zimbabwe was also found to be generally due to poor calf management, among other factors (Agyeman and Nkhonjera, 2002).

Poor production and marketing infrastructure has also been a major operational problem among smallholder dairy farmers. According to Archibald (2009) dairy production requires substantial capital investment and milk, the major output, is highly perishable and requires good cold storage facilities, hygienic milking conditions and proper transportation, and the absence of such infrastructure can result in considerable losses. Transportation is essential for marketing. Enhancing the ability of poor smallholder dairy farmers to reach markets and actively engage in them posed a pressing dairy development challenge in Suriname (Nifeg, 2011). Tedla (2001) notes lack of capital for purposes of investing in production and marketing infrastructure as the most important single factor affecting dairy farming viability. Related to lack of capital is also the problem of lack of managerial and organizational skills required in using whatever capital is made available. Bouman (2003:45) for example observes that: "To lend money to entrepreneurs who lack managerial capacity is merely to throw it away". In Enugu North Agricultural Zone of Enugu State, Nigeria, smallholder dairy farming has remained more subsistence than commercial due, largely, to limited access to credit (Ajayi, 2010). Insecure land tenure systems have also often been blamed for the low productivity of most resettlement schemes (World Bank, 1991).It is argued that because of the temporary and therefore insecure nature of the permit form of land ownership and control obtaining in most resettlement areas, experienced farmers are not always willing to invest in these areas while potential credit providers are, on the other hand, equally reluctant to offer loans to farmers producing on land that lacks collateral value.

\section{Methodology}

Both qualitative and quantitative primary data were collected from the study population. Data were collected by means of both structured and semi-structured questionnaires as well as through interviews and observations. Data were collected over a period of three (3) months from January 2013 to March 2013. The target population for this study consisted of all the 345 households registered on the dairy scheme. A list of the farm households was supplied by the scheme's management. From this list, a sample of 75 farm household units was randomly targeted with questionnaires. The 75 household units provided a sample size of more than $20 \%$. Questionnaires were administered to sampled farmers by 5 trained enumerators with each enumerator administering 15 questionnaires in 7 days.

For qualitative data, a total of 24 key informants were conveniently selected on the basis of accessibility and willingness to participate. The key informants were selected from among members of the management, scheme development committee and extension staff. Observations were also made during the field visits that took place after interviews with the farmers. These included visits to breeding pens, dairying points, processing facilities and milk collection centers (MCCs).

\section{Research Findings}

Significant positive changes in the livelihood of dairy farm households were noted during the study. Mayfield Dairy Scheme had, for example, managed to create employment, improve incomes and enhance the asset position of the farm families resettled on the scheme. In addition, a good number of smallholder farmers on the scheme confirmed that they had gained valuable skills and knowledge in farm management. As part of the land resettlement and reform programmme in the country, the scheme had also managed to reduce over crowdedness in the adjacent communal lands. However, the above positive changes notwithstanding, a myriad of operational challenges working against the ability of the scheme to operate at an optimal level were also noted during the study. Presented and discussed below are some of the major operational challenges noted: 


\section{Lack of adequate capital}

As already noted in the literature reviewed above, dairy operations are highly capital intensive in nature. Substantial amounts of funds are required in the form of both investment and working capital. During the study, 78 percent of the farmers reached pointed out that they sometimes borrowed money for their dairy operations from formal lending institutions with ARDA's Loan Revolving Fund being cited in the study as the major source of credit for most farmers. Friends or Neighbours and Savings Clubs were also cited as some of the other major sources of credit for dairy farmers at the scheme. Below is a graphical distribution of the borrowed funds by source:

Fig: 1: Source of borrowed funds

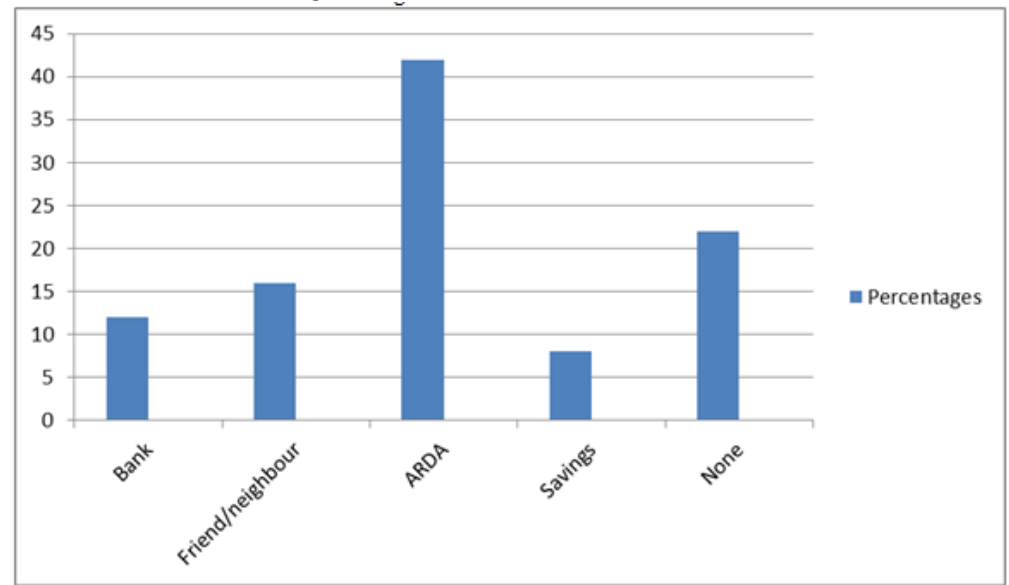

Source: Field Data, March 2013

While own-savings through the agency of savings clubs is, in scholarly circles, widely touted as the most sustainable source of project finance, own-savings did not find much favour with the majority of farmers at Mayfield Dairy Scheme. The inflationary and unstable macro-economic environment which gripped the country during the period 2000 to 2008 was cited as one of the major reasons why farmers lacked confidence in savings clubs. It is also common cause that an inflationary macro-economic situation is a natural disincentive to savings.

Also important to note is that while a significant percentage $(78 \%)$ of farmers had access to loans, both formal and informal, the loan amounts received were said to be generally small and the loan advances irregular and less frequent. Credit among the farmers was also affected by the problem of fungubility or exchangeability whereby a significant chunk of the borrowed funds was often used for consumption instead of financing dairy farming operations. Evidence of fungubility is clearly captured in the graph below where a substantial $26 \%$ of borrowed funds went towards paying school fees.

Fig. 2 : Uses of borrowed money

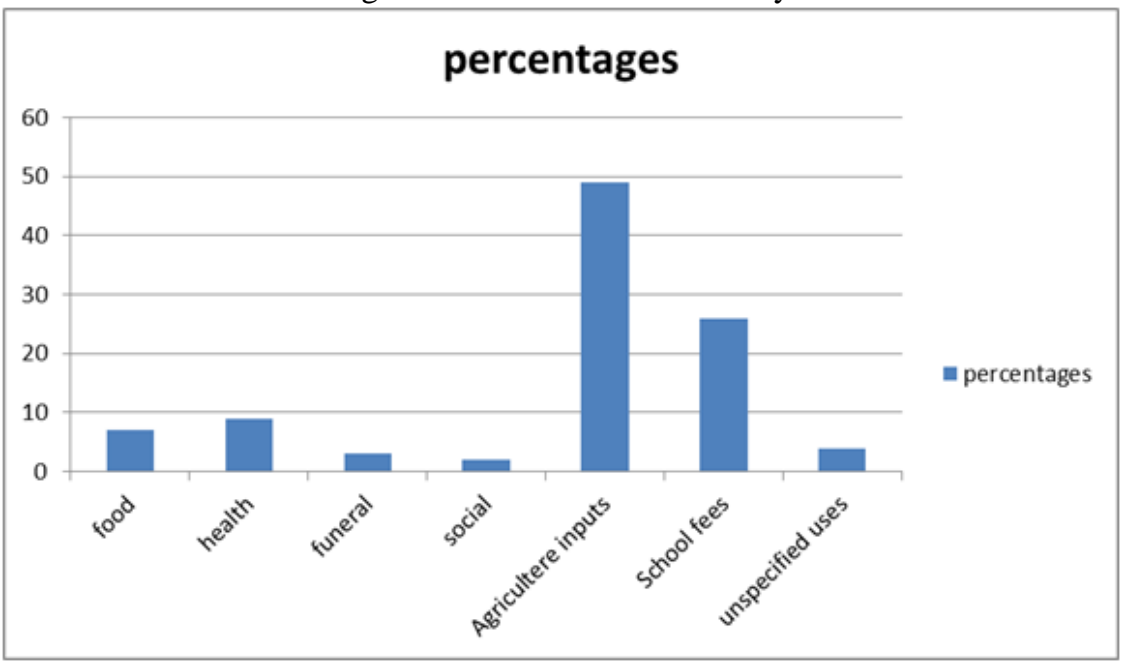

Uses of borrowed money

Source: Field Data, March 2013 
Lack of capital did adversely affect investment in dairy livestock. For example, a significant percentage (22\%) of the farmers indicated that they could not expand their dairy herd because of lack of capital, a problem also confirmed by the extension workers. Farmers at the scheme were also finding it difficult to purchase calf crossbreed heifers because of the high cost involved. In addition, lack of funds also affected the ability of farmers to deal with tick borne diseases due to an erratic dipping programme caused by the inability of the farmers to acquire dipping chemicals. This, reportedly, led to the deaths of quite a number of cows during the year prior to the study. 16 per cent of the farmers cited cattle diseases as a major dairy production constraint.

\section{Lack of adequate extension support}

While only 18.7 percent of the farmers complained of poor contact with ARDA extension staff, the extension workers themselves pointed out that extension coverage was greatly curtailed by the poor road network at the scheme. The extension staff used motor cycles when reaching out to farmers and both the farmers and extension staff intimated that some areas in the scheme were totally inaccessible even on a motor cycle. The extension staff also pointed out that the motor cycles that they were using were becoming more and more expensive to run because of the high poor road network-induced wear and tear as well as constant breakdowns the motor cycles were subjected to when visiting farmers. Cited during the study was also the problem of poor farmer-extension staff relations dating back to 2000 when most farmers protested against ARDA's management of the scheme. According to the protesting farmers, ARDA's continued presence at the scheme smacked of state control and interference, and therefore unacceptable. Although at the time of conducting the study relations between farmers and extension staff were reportedly somewhat on the mend, the extension workers confessed that they had at one point stopped visiting farmers after the latter had threatened them with physical bodily harm.

\section{Poor farm management practices}

Poor management practices also affected operations of Milk Collection Centres (MCC). 57.3\% of the farmers complained of poor management of the MCCs .The committees running the MCCs were accused of mismanagement of farmers' milk incomes. The scheme management and extension staff handed over the running of the MCCs to the farmers in 2000. This was done after the farmers had, as pointed out above, fought for the control of the MCCs. The MCCs were responsible for collecting milk from the farmers, bulking it and delivering it, on behalf of the farmers, to Dairiboard Zimbabwe Limited (DZL), a state-owned company dealing with commercial milk processing, packaging and wholesale marketing in the country. Mayfield Dairy smallholder farmers contributed US \$ 13-00 every month towards the cost of running these MCCs. The capacity to effectively manage cooperative business, however, seemed to be limited among the farmers.

Failure to properly keep farm records was identified as a major management problem affecting dairy operations at Mayfield. Although the farmers were expected to keep records on all their operations, the majority did not. Discussions with key informants and the farmers revealed the following as essential records in need of keeping: Profit and Loss or Income and Expenditure Records, Daily Milk Production Records, Cattle Records, Artificial Insemination Records, Calving Records, Disease and Mortality Records, Crop Records, and Farm Diaries.

Twenty eighty percent (28 percent) of the sampled farmers did not keep any records at all. The remaining 72 percent kept some records although most of these records were last updated as way back as 2008, about five years prior to the study. The failure by farmers to properly keep farm management records had serious implications on their operations. Record keeping is one important way through which performance can be monitored and evaluated and it is through performance monitoring and evaluation that appropriate improvements to dairy farm operations could be made. The records are also important when sourcing credit as these are, invariably, used to assess farm credit worthiness. Lack of up-to-date farm management records could also be attributable to inadequate extension support. Given the high number of records to be kept and in light of the generally low levels of education among the farmers, close monitoring through increased extension support was therefore critical. The low level of education is clearly evidenced by the fact that only $14,7 \%$ of the research participants had a post-primary education of some sort.

\section{Poor production and marketing infrastructure}

The poor road network alluded to above, which had deteriorated into dangerous gullies, greatly affected the ferrying of inputs such as feeds to farms and the delivery of milk to Milk Collection Centres (MCCs). Scheme management and extension reports indicated that the roads servicing the dairy scheme had last been serviced some 5 to 6 years prior to the study. At planning, milk delivery from the farms to the MCCs was left to farmer initiative. It was envisaged that as farmers increased milk output, sales and incomes, they would then form their own transport cooperatives for purposes of ferrying milk from the farms to the MCCs. However, due to below par production, this had not been the case. Most farmers were located on average three or more 
kilometers away from the MCCs and during the study it was observed that the roads servicing some areas were not accessible even on ox-driven or donkey-driven carts.

Thus, the poor state of roads served as a real disincentive to increased production at Mayfield dairy settlement scheme. The researchers learnt of one case of a farmer who transported on average 80litres of milk for a distance of over 3.5 kilometers daily on foot. It was also discovered that the National Dairy Cooperative (NDC) had, just before the study, threatened to withdraw its Bulk Milk Collection service as it had become very expensive to provide the service due to high vehicle maintenance costs caused by the poor state of the roads. There were also numerous other services which were being affected by this poor road infrastructure. For example, veterinary, education and health officials were also finding it difficult to visit the area and bus companies had also since withdrawn their services to the area.

Apart from poor road infrastructure there was also the issue of water supply. Sixty four percent (64\%) of the farmers complained of poor water supplies during the dry season. Water was supplied to the farmers from three points. These points were Fern Creek for Area 5 and 6, Knutsford for Area 4 and Upper Randfontein for area 1 to 3. Basing on scheme management and extension staff reports, areas 4 and, 5 and 6 normally experienced water supply problems during the dry season. This was caused by the low water levels in the weirs. There were also cases of water diversion by adjacent communal areas in the catchment areas. Some farmers were also said to be tampering with the water pumps and this therefore increased the incidences of water pump breakdowns. Siltation of the weirs was also another challenge causing water supply problems at the scheme. This water supply problem adversely affected fodder production during the dry season and low fodder production, in turn, affected overall milk output.

The study also looked at alternative sources of water supply. A total of $66.7 \%$ and $33.3 \%$ of the households reported that they resorted to well water and river water respectively when their pipes ran dry. The farmers complained that some of these alternative sources of water supply were far away from their farms and that there was also a high risk of water borne diseases emanating from these unprotected and therefore unhygienic water bodies.

\section{Poor Social Relations}

Social conflicts were identified by most farmers as one of the major problems affecting effective management and leadership by most farmer committees. Farmer committees were incapacitated by power struggles with most of these power struggles appearing to be based on ethnic differences. The scheme management and extension staff identified a total of eight ethnic groups in the project and it was noted that different power hungry leaders rallied some ethnic groups of farmers against other ethnic groups of farmers purely for the leaders' own individual selfish political ends. Group cohesion was, thus, a real operational challenge at the scheme.

As already referred to above, conflicts between ARDA staff and the farmers were also noted during the study. These conflicts were said to have resulted in a number of farmer uprisings since the scheme's inception. The farmers were also divided over the continued presence of ARDA at the scheme. Some farmers felt that it was high time ARDA withdrew its management personnel from the scheme. Their argument was that, as farmers, they were now experienced enough on issues to do with general management and what they only needed was extension services to take care of the technical side of production. There farmers also argued that most donor and government funds earmarked for the project were being diverted towards meeting the salaries of ARDA personnel at the expense of the farmers' dairy operational needs. The farmers also accused ARDA staff of constantly threatening them with eviction should they violate any of the provisions of the land ownership permits and that since the 2000 farmer revolt, ARDA management and extension staff seemed now to be biased in favour of those farmers who had not been taking part in the protests. The farmers were also against ARDA's failure to consult them on major management decisions as well its refusal to allow them to diversify into nondairy operations.

However, some farmers were in favour of ARDA's continued management of the scheme arguing that the parastatal's presence would help in diffusing ethnic tensions among the farmers thereby guaranteeing sustainability of the scheme. These farmers also pointed out that ARDA was providing a valuable link between them and other service institutions like donors, veterinary service providers and such financial lending institutions like the government-owned AGRIBANK. While attributing conflict and lack of cohesion among farmers mainly to poor beneficiary selection, some of the extension workers, however, admitted that their own command style of management was also partly to blame for the social disharmony and 'rebellious' behavior at the scheme. On poor beneficiary selection, extension workers argued that some farmers only came to the project just to acquire land for residential purposes and were not prepared to work hard for the cause of the scheme as a collective commercial dairy entity. 


\section{Insecurity of Tenure}

One of the major issues of concern in resettlement areas in Zimbabwe is the security of land tenure. The nature of the users' rights and obligations over given pieces of land is one of the major factors affecting land use productivity or efficiency. The permit system of tenure in the country's resettlement areas has generally been found to be highly insecure. Tenure insecurity emanated from the fact that the permits given to farmers did not indicate the period for which the permits were valid, and did not address issues relating to inheritance, sale or renting out of the land. Although not much evidence was available to suggest that this tenure system had led to under investment at Mayfield, $13 \%$ of the farmers interviewed expressed concern over land tenure insecurity which they said discouraged them from investing in long term agricultural improvements on the farms while at the same time leading to poor land resource management by the settlers.

\section{Conclusion}

In conclusion, it should be noted that while dairy farming at Mayfield Dairy Settlement Scheme has succeeded in improving rural livelihoods in the area, operations at the scheme were, however, far from being satisfactory. Major operational problems affecting the scheme included lack of capital, poor production and marketing infrastructure, lack of farmer involvement in production planning, weak general management practices, inadequate extension support, insecurity of land tenure, and lack of adequate social capital as evidenced by poor social relations of production at the scheme. A review of literature above has already shown that these problems are not unique to Mayfield but have indeed affected smallholder dairy operations elsewhere in Zimbabwe as well as in other less developed countries like Kenya, Bolivia, Suriname, Nigeria, Cote d'voire, Mali and Tanzania, to name only a few. The universality of these problems demonstrates how real these problems are. As such, Zimbabwe and other countries in similar development situations need to seriously and urgently address these operational bottlenecks if rural livelihoods and national economies are to be uplifted and improved in these countries. The dairy industry in Zimbabwe at the time of conducting the study was, for example, operating at 45 percent capacity, producing 51 million litres of milk annually against a national demand of around 120 million litres, with the deficit being covered by imports mainly from South Africa and other neighbouring countries (Chawafambira, 2013). Increase in domestic milk output through commercialization of smallholder dairy farming would, therefore, go a long way in reducing the total milk import bill in the country, thereby improving the national current account balance.

\section{References}

[1]. Agyeman, K. \& Nkonjera, L. P.(2002). 'An evaluation of the productivity of cross bred dairy cattle on smallholder and government farms in Southern Africa' in ILCA Research Report No.12. ILCA, Addis Ababa.

[2]. Ajayi, H (2010). 'Towards a Production Function for Dairy Farms' in The Farm Economist, Vol 111. No. 1. The Agricultural Economics Research Institute, Oxford.

[3]. Archibald, P (2009). Production Functions for Dairy Farming and Their Applications, The Agricultural Institute, Oxford.

[4]. ARDA (1989). Mayfield Dairy Settlement Scheme: Annual Progress Report for November 1988 - October 1989.

[5]. Arusei, N (2012). "Building the political case for agro-industries and agribusiness in developing countries", World Development 31(11): 1809-1827.

[6]. Bassett, T(1994). The economic impact of public policy on smallholder farmers in and around Cote d'vure, The Johns Hopkins University Press, Baltimore.

[7]. Bouman, R (2003) . Economic Analysis of Agricultural Projects, John Hopkins University Press, Baltimore and London.

[8]. Cahaca,W (2000). "Poverty Alleviation and Rural Development in Tanzania, with particular Reference to Changes in Agrarian Structure in the Karega region", Journal of Mountain Science 13(3): 123- 134.

[9]. Chawafambira, K (2013). Zim spends \$6m on milk imports, http://www.dailynews.co.zw [Accessed on 5 Decemeber 2013]

[10]. Crotty R. (1999).Cattle, Economics and Development, Commonwealth Agricultural Bereaux, England.

[11]. Gittinger, J.P (1997). Economic Analysis of Agricultural Projects. Johns Hopkins University Press, Baltmore and London.

[12]. Hale D.H. (2001). "Dairy Manpower Development Survey for Zimbabwe." In Mann E.J. and Brookes (eds). Dairy Development Policy and Implementation: Sharing of Experiences between Africa and Asia, (Seminar proceedings) FAO, Rome.

[13]. Henk, T et al (2007). How to make a milk market: A case study from the Ethiopian Highlands, Socio- economic and Policy Research Working Paper 28, International Livestock Research Institute (ILRI), Addis Ababa.

[14]. Johnson D.T. (1996).The Business Farming: A guide to farm business management in the Tropics, Macmillan publishers ltd, London and Babingstoke.

[15]. Mahood, C(2009). Assessing participation in Development. Konark, Delhi.

[16]. Matinhira, E. (1988). Economics of Milk Production on small scale commercial farms in Zimbabwe: The case study of the Marirangwe Dairy project, (Unpublished BSc Agriculture Honours degree study project).

[17]. Mayfield Dairy Settlement Scheme (1986). Annual Progress Report for November 1985 - October 1986.

[18]. Mdoe, K \& Mlay, R (2009). "Farmers" perception and adoption of new agricultural technology: Evidence from analysis in Kenya". Agricultural Systems, 55 (3), 409-423.

[19]. Milliken, M. (2000).Dairying in Bolivia: A socio-Economic survey, Oxford University press, Oxford.

[20]. Mugwagwa, J(2001). Keys to Inclusion of Small Producers in Dynamic Markets in Marirangwe . In Mann E.J. and Brookes (eds). Dairy Development Policy and Implementation: Sharing of Experiences between Africa and Asia, (Seminar proceedings) FAO, Rome.

[21]. Ngetha, M.W. (2000). Development Trends on Small Scale Milk Production and Processing. Cambridge University press, Cambridge. 
[22]. Nifeg, B(2011). “Potential and Prospects of Dairy Business in Suriname.” Agricultural Economics Research Review, 20 (4), 489-502.

[23]. Norman, L and K.R, Wilson (1996). The Farm Business. Longman, London

[24]. Roth, M (1990). "Land Tenure Investment in African Agriculture: Theory and Evidence." Madison, WI: Land Tenure Center Paper 151.

[25]. Shepherd,A(2007). A People Centred Approach to Reducing Poverty, Blackwell, Oxford.

[26]. Slater.(1997).The Principles of Dairy farming, Farming Press Books, London.

[27]. Teddla, A (2001). Dairying. Macmillan, London.

[28]. Wambugu, M (2007). "Climatic and Environmental Factors Affecting Dairy Productivity". In Smallholder Dairying in the Tropics. ILRI, Nairobi.

[29]. World Bank (1991). The State of Food and Agriculture, Washington

[30]. World Bank (1997). Zimbabwe Agriculture Sector Memorandum. Vol 11: Main Report Report No. 9429-Zim. 